\title{
Onkoloji hastalarında kemoterapi öncesi HBsAg, antiHBs ve izole antiHBc IgG pozitiflik oranları
}

\author{
The positivity ratios of $\mathrm{HBs} A g$, anti-HBs and isolated anti-HBc IgG before chemotherapy
}

\author{
Nagehan Didem Sarı, Rıza Umar Gürsu
}

Gönderilme tarihi:11.04.2019

Kabul tarihi:09.07.2019

\section{Özet}

Amaç: Onkoloji hastalarında uygulanan kemoterapi HBV reaktivasyonuna neden olabilmektedir. Bu çalışmada amacımız hastanemiz Onkoloji Polikliniği'nde takip edilen ve kemoterapi alması planlanan hastalarda kemoterapi öncesinde HBV enfeksiyonu açısından yapılan tarama sonuçlarını değerlendirmektir.

Gereç ve yöntem: Bu çalışmada Ocak 2014-Aralık 2018 tarihleri arasında, Sağlık Bilimleri Üniversitesi İstanbul Eğitim ve Araştırma Hastanesi Medikal Onkoloji Polikliniği'ne başvuran ve kemoterapi alması planlanan, HBV serolojileri taranmış, 544 hasta değerlendirmeye alındı. Hastaların yaş, onkolojik tanıları, HBV enfeksiyonu açısından HBsAg, antiHBs ve antiHc IgG sonuçları geriye dönük olarak tarandı.

Bulgular: Hastaların tamamından HBsAg istenmiş olduğu belirlenmiş olup, 16'sında (16/544) \%2,94 HBsAg pozitifliği görüldü. AntiHBs istenen hasta sayısının 158 olduğu ve bu hastalardan 51'nin pozitif \%32,27 (51/158) olduğu, izole antiHBc IgG pozitiflik oranının ise 4/50 (\%8) olduğu belirlendi. HBsAg pozitif 16 hastanın malignite dağılımlarına bakıldığında en sık akciğer ve gastrointestinal kanser olduğu görüldü.

Sonuç: Kemoterapi planlanan hastalarda HBV reaktivasyonu ve bunun sonucu olarak gelişen karaciğer yetmezliği, başlanan tedaviye ara verme gibi istenmeyen bir tabloya yol açabilir. Bu durum göz önüne alınarak hastaların HBV enfeksiyonu açısından taranması ve immunsüpresif tedavi uygulayan hekimlerin bu konuda farkındalığının arttırılması gerekmektedir.

Anahtar Kelimeler: Onkoloji, kemoterapi, HBV.

Sarı ND, Gürsu RU. Onkoloji hastalarında kemoterapi öncesi HBsAg, AntiHBs ve izole AntiHBc pozitiflik oranları. Pam Tıp Derg 2019;12:407-410.

\begin{abstract}
Purpose: Chemotherapy may cause HBV reactivation in oncology patients. This study was aimed to evaluate screening results for HBV infection before chemotherapy in patients who are being followed-up and planned to receive chemotherapy in the oncology clinic.

Materials and methods: This study included 544 patients who are admitted to the Health Sciences University Istanbul Training and Research Hospital Medical Oncology Outpatient Clinic between January 2014 and December 2018, planned to receive chemotherapy. Age, diagnoses, HBsAg, anti-HBs and anti-HBc lgG results were screened retrospectively for HBV infection.

Result: When a total of 544 patients who were planned to receive chemotherapy were analyzed with regard to cancer type, lung and gastrointestinal cancers were found to be most common. It was determined that $\mathrm{HBsAg}$ was screened in all. HBsAg positivity ratio of our patients was 2,94 \% (16/544), anti-HBs positivity was found as $32,27 \%(51 / 158)$, the rate of isolated anti-HBc lgG was $4 / 50(8 \%)$.

Conclusion: Results of this study considering the risk factors such as reactivation, hepatic failure, interruption of treatment in patients who are scheduled for chemotherapy, we think that the patients should be screened for HBV infection and the awareness of physicians who apply immunosuppressive treatment study should be increased.
\end{abstract}

Key Words: Oncology, chemotherapy, HBV.

Sarı ND, Gürsu RU. The Positivity Ratios of HBsAg, AntiHBs and isolated anti-HB in patients with canser prior to chemotherapy. Pam Med J 2019;12:407-410.

Nagehan Didem Sarı, Uzm. Dr. İstanbul Eğitim Araştırma Hastanesi, Enfeksiyon Hastalıkları ve Klinik Mikrobiyoloji Kliniği Fatih/ISTANBUL e-posta: drdidemsari@hotmail.com (orcid.org/0000-0002-9400-0997)

Rıza Umar Gürsu, Uzm. Dr. İstanbul Eğitim Araştırma Hastanesi Medikal Onkoloji Kliniği Fatih/iSTANBUL e-posta: rumarg80@gmail.com (orcid. org/0000-0002-6331-3632) 


\section{Giriş}

Hepatit B virüsü (HBV) infeksiyonu, tüm dünya nüfusunu ilgilendiren küresel bir sağlık sorunudur. Dünya'da her üç kişiden birinin HBV ile karşılaştığı bilinmektedir [1]. Viral hepatitlerin klinik seyrini HBV'nin viral replikasyonu ile konakçının immün cevabı belirlemektedir. AntiHBs (HBV yüzey antijenine karşı gelişen antikor) gelişerek, serolojik olarak tam iyileşme sağlansa da, viral genom konağın hepatosit nükleosunda kalmaya devam etmektedir. İmmun sistemin baskılanması durumunda HBV reaktivasyonu ve akut alevlenme gelişebilmektedir. HBV reaktivasyonu kişiden kişiye farklı klinik tablolarla ortaya çıkabilir. Asemptomatik AST (aspartat aminotransferaz), ALT (alanin aminotransferaz) yüksekliği olabileceği gibi, fulminan hepatitle hasta kaybı bile görülebilir. Ayrıca reaktivasyon gelişmesi, kemoterapinin kesilmesine ve primer hastalık tedavisinin gecikmesine neden olabilmektedir. $\mathrm{Bu}$ nedenle hepatit takip ve tedavisine yönelik yayınlanmış birçok güncel kılavuz immunsüpresif tedavi öncesinde HBsAg (HBV yüzey antijeni), AntiHBc IgG ve HBV DNA bakılmasını önermektedir [2-4].

Bu çalışmada amacımız hastanemizde takip edilen onkoloji hastalarında kemoterapi öncesi HBsAg, antiHBs ve izole antiHBc IgG pozitiflik oranlarını değerlendirmektir.

\section{Gereç ve yöntem}

Bu çalışmaya Ocak 2014-Aralık 2018 tarihleri arasında Sağlık Bilimleri Üniversitesi İstanbul Eğitim ve Araştırma Hastanesi Medikal Onkoloji Polikliniği'ne başvuran ve kemoterapi planlanan 544 hasta alındı. Hastaların yaş, onkolojik tanıları, HBsAg, anti $\mathrm{HBs}$, antiHBc IgG sonuçları hastane elektronik bilgi yönetim sistemi kayıtlarından ve hasta dosyalarından retrospektif olarak tarandı. HBsAg, antiHBs (Triturus MikroELISA, Grifols, Madrid, İspanya) ve antiHBc IgG (Architect AntiHBc IgG Kiti Architect plus i2000 SR, Abbott, Berlin, Almanya) firma önerileri doğrultusunda çalışıımıştı.

Çalışma ile ilgili İstanbul Eğitim ve Araştırma Hastanesi Etik Kurulu'ndan 28/06/2019 tarih ve 1895 kayıt numarası ile onay alındı.

\section{Bulgular}

Çalışmaya \%46,3;ü $\quad(n=252)$ kadın, yaş ortalaması 62,5 yıl olan 544 hasta dahil edildi. Hastaların tümünden $\mathrm{HBsAg}$ istenmiş olup, HBsAg pozitifliği \%2,94 (16/544) oranında saptandı. AntiHBs istenen olgu sayısı 158 olup, istenme oranının \%29 (158/544) olduğu gözlendi. Bu olguların \%32,27'sinde (51/158) antiHBs pozitifti. AntiHBs pozitif olguların $\% 10,12$ (16/158)'sinden antiHBc IgG istenmiş olup, $\% 5,6$ 'sında (8/158) pozitiflik saptandı. İzole antiHBc IgG pozitiflik oranının ise 4/50 (\%8) olduğu belirlendi. HBsAg pozitifliği saptanan 16 hasta değerlendirildiğinde en sık görülen malignitenin $(\% 43,75)$ akciğer kanseri olduğu saptandı. HBsAg pozitif olgularımızın malignite tür dağılımı tablo-1'de belirtilmiştir. HBV infeksiyonu serolojik bulgusu olan 20 hastadan sadece 'sine Enfeksiyon Hastalıkları ve Klinik Mikrobiyoloji hekimi ile görüşülerek antiviral profilaksi başlanmıştı. Hastaların tamamında HBV reaktivasyonu açısından immunsüpresif tedavileri orta risk kategorisinde bulunmaktaydı ve hiçbir hastada HBV reaktivasyonu gözlenmedi.

Tablo 1. HBsAg pozitif olgularımızın malignite dağılımı.

\begin{tabular}{lllllll}
\hline Kanser Türü & Akciğer & Gis & Prostat & Böbrek & Meme & Over \\
\hline Sayı & 7 & 5 & 1 & 1 & 1 & 1 \\
Yüzde & $\% 43,75$ & $\% 31,25$ & $\% 6,25$ & $\% 6,25$ & $\% 6,25$ & $\% 6,25$ \\
\hline
\end{tabular}




\section{Tartışma}

Sistemik sitotoksik kemoterapi uygulanan inaktif HBV taşıyıcılarında viral reaktivasyon gelişme oranının \%20-\%70 ve mortalitenin \%5-\%40 olarak değişebileceği bildirilmiştir [2]. $\mathrm{Bu}$ nedenle Avrupa Karaciğer Araştırmaları Derneği'nin 2017'de yayınlanan kılavuzunda, kemoterapi planlaması yapılmadan önce kemoterapi ve immünosüpresif tedavi alacak olan tüm hastaların $\mathrm{HBsAg}$, antiHBs ve antiHBc IgG yönünden taranması ve HBsAg pozitif olanlara entekavir, tenofovir disoproksil fumarat ya da tenofovir alafenamid gibi potent bir antiviral ajanın başlanması önerilmektedir. Antiviral ajan kullanımı sırasında ve tedavi kesilmesini takip eden 12 ay boyunca 3-6 ayda bir kez karaciğer enzimleriyle birlikte HBV DNA kontrolü yapılması gerektiği belirtilmiştir [2].

Amerikan Gastroenteroloji Derneği'nin kılavuzda ise HBV reaktivasyonu gelişme olasılığı, immünosüpresif ajana ve hepatit serolojisine göre düşük, orta ve yüksek olmak üzere üç grupta kategorize edilmiştir. HBsAg ve/ veya antiHBc IgG pozitif olan antrasiklin grubu kemoterapötik ajan, rituksimab veya yüksek doz steroid kullanan hastalar yüksek riskli kabul edilmiş; bu hastalara antiviral profilaksi başlanması önerilmiştir [5]. Ülkemizden 2016 yılında Engin ve ark. [6] yapmış olduğu çalışmada, immunsüpresif tedavi alan toplam 445 hastanın, \%23,3'nde $\mathrm{HBsAg}$, antiHBs ve antiHBc IgG'nin birlikte tarandığı saptanmıştır. Çalışma grubumuzu oluşturan 544 hastanın tamamından HBsAg istenmiş, \%2,94 (16/544) HBsAg pozitifliği gözlenmiştir. $\mathrm{Bu}$ oran toplumumuzdaki serolojik taramalarla benzerlik göstermektedir. AntiHBs istenen 158 olguda pozitiflik oranı \%32,27 olup bu oranda paraleldir. Ancak çalışmada HBsAg, antiHBs ve antiHBc IgG'nin tamamının bakılabildiği hastaların oranı sadece \%7,53 (41/544) olup bu oran son derece düşüktür.

Eren ve ark.'nın [7] 2009 yılında, kemoterapi alan hastalarda yaptıkları bir çalışmada, HBsAg pozitifliği \%5 olarak belirlenmiş ve toplam 49 hastadan 9'unda HBV reaktivasyonu olduğu, HBsAg pozitif hastaların \%88'inin solid tümör olduğu bildirilmiştir.

İran'dan Meidani ve ark'nın [8] hematoloji onkoloji kliniğinde, kemoterapi ve radyoterapi alacak 213 hasta ile yürüttüğü, yaş ortalaması 47,7 yıl ve \%54'ü erkek olan bir çalışmada hastalarda sıklık sırasıyla meme, gastrointestinal tümör, baş-boyun tümörü ve lenfoma (sırasıyla \%29,1; \%19,7; \%13,6 ve $\% 6,6)$ olduğu belirlenmiştir. Toplam 213 olgudan 2'sinde $(\% 0,9) \mathrm{HBsAg}$ pozitifliği tespit edildiği, $\% 2,8$ (6/213) olguda ise izole antiHBc pozitifliği olduğu belirlenmiştir [8]. İnci ve ark. [9] solid tümörlü hastalarda yaptığı çalışmada ise $\mathrm{HBsAg}$ pozitiflik oranı \%3,6 iken antiHBc pozitiflik oranı \%38,6 olarak bildirilmiştir. Konuyla ilgili yapılan bir diğer çalışmadaysa kemoterapi alacak olan 208 hastanın sadece \%14'üne kemoterapi öncesi HBsAg testi yapıldığı bildirilmiştir [10]. Köse ve ark. [11] onkoloji hastaları ile yapmış olduğu çalışmada HBsAg pozitifliği $\% 4,8$ ve antiHBs pozitiflik oranı \%34,6 olarak bulunmuştur. Oğuz ve ark. [12] solid tümörlü hastalarla yapmış olduğu çalışmada ise HBsAg ve anti HBs pozitiflik oranları sırasıyla \%4,4 ve \%36,8 olduğu belirlenmiştir. Epidemiyolojik dağılım olarak bizim çalışmamızda da benzer sonuçlara ulaşılmıştır. Konuyla ilgili yapılan bir meta analizde ise HBsAg pozitif meme kanserli hastalarda lamivudine profilaksinin HBV reaktivasyonu ve HBV ile ilişkili morbidite ve mortalitenin azaltılmasında etkili olduğu belirtilmiştir [13]. HBV enfeksiyonu serolojik bulgusu olan 20 hastadan sadece iki hastaya antiviral profilaksi başlandığı saptanan bu çalışma sonrasında Medikal Onkoloji Kliniği ile ortak eğitimler planlanmıştır.

Serolojik olarak antiHBc IgG pozitif, HBsAg negatif, antiHBs negatif olan olgularda okkült HBV enfeksiyonu akla gelmelidir. Okkült HBV enfeksiyonu, dolaşımda saptanabilir HBsAg olmamasına rağmen, kanda ve karaciğer dokusunda HBV DNA düzeyinin $200 \mathrm{IU} / \mathrm{ml} \leq$ olması olarak tanımlanmaktadır. Sağlıklı kan donörlerinde HBV DNA bakılarak yapılan çalışmalarda, okkült HBV enfeksiyonunun prevalansının \%1,6-\%38 gibi farklı oranlarda belirlendiği bildirilmektedir [14-16]. Bu durum çalışmaların yapıldığı bölgelerdeki HBV seroprevalansı ile ilişkili olabilir. Çalışmamızda izole antiHBc IgG pozitiflik oranı \%8 olduğu belirlenmiş, ancak hastaların hiçbirinde HBVDNA bakılmadığı için okkült hepatit değerlendirmesi yapılamamıştır. AntiHBc IgG dahil edilmeden yapılan serolojik taramalar, HBV prevalansının düşük olduğu ülkeler haricinde, okkült HBV veya 
geçirilmiş enfeksiyonu olan kişilerin önemli bir bölümünün gözden kaçmasına neden olacaktır $[17,18]$.

$\mathrm{Bu}$ çalışmanın başlıca kısıtııı̆ı verilerin geriye dönük olarak elde edilmesidir. $\mathrm{HBsAg}$ istenen tüm olgular çalışmaya dahil edilirken, bu olgularda antiHBs ve antiHBc IgG taranma oranları sınırlıdır. Hastaların HBV reaktivasyonu açısından değerlendirilmeleri de geriye dönük olarak yapılımıştır.

Sonuç olarak, kemoterapi planlanan hastalarda HBV reaktivasyonu, karaciğer yetmezliği, kemoterapiye ara verme gibi risk faktörleri de göz önünde bulundurularak tedavi öncesi dönemde HBV serolojisi mutlaka araştırılmalı ve gerekli profilaksiler başlanmalıdır. İmmunolojik olarak hassas olan bu hasta grubunda, gerekli değerlendirmelerin uygun şekilde yapılması için multidisipliner bir yaklaşım sergilenmesi gerekmektedir.

Çıkar Illişkisi: Yazarlar herhangi bir ilişkisi olmadığını beyan eder.

\section{Kaynaklar}

1. Loomba R, Liang TJ. Hepatitis B rectivation associated with suppresive and biological modifier therapies: Current concepts, management strategies, and future directions. Gastroenterology 2017;152:1297-1309. https://doi.org/10.1053/j.gastro.2017.02.009

2. European Association for the Study of the Liver. EASL 2017 Clinical practice guidelines on the management of hepatitis B virüs infection. J Hepatol 2017;67:370398. https://doi.org/10.1016/j.jhep.2017.03.021

3. Lubel JS, Angus PW. Hepatitis B reactivation in patients receiving cytotoxic chemotherapy; diagnosis and management. J Gastroenterol 2010;25:864-871. https://doi.org/10.1111/j.1440-1746.2010.06243.x

4. Yeo W, Johnson PJ. Diagnosis, prevention and management of hepatitis $B$ reaktivation during anticancer therapy. Hepatology 2006;43;209-220. https://doi.org/10.1002/hep.21051

5. Reddy KR, Beavers KL, Hammond SP, Lim JK, FalckYtter YT. American Gastroenterological Association Institute. American Gastroenterological Association Institute guideline on the prevention and treatment of hepatitis $B$ virus reactivation during immunosuppressive drug therapy. Gastroenterology 2015;148:215-219. https://doi.org/10.1053/j.gastro.2014.10.039

6. Engin B, Günay S, Binicier ÖM, Derviş Hakim G, Yıldız $C$, Paköz ZB. İmmünsüpresif hastalarda hepatit $B$ virüs tarama sıklığı ve gerçek yaşam verileri. FNG \& Bilim Tıp Dergisi 2016;2:256-259. https://doi.org/10.5606/ fng.btd.2016.046
7. Eren OO, Artac M, Boruban MC, Yavas O, Arslan U, Basaranoglu M. Chemotherapy-induced hepatitis B virus reactivation in $\mathrm{HBsAg}$ positive cancer patients: a single center experience. Med Oncol 2009;26:386-392. https://doi.org/10.1007/s12032-008-9133-4

8. Meidani M, Rostami M, Hemmati S, et al. Screening and evaluation of chronic and occult hepatitis B in chemo - radiotherapy patients with cancer. Adv Biomed Res 2016;5:85. https://doi.org/10.4103/2277-9175.182216

9. İnci A, Açıkgöz Ö, Kalaycı M, Ülker V. Meme ve jinekolojik kanserli hastalarda kemoterapi öncesi HBsAg, antiHBs ve izole antiHBc pozitiflik oranları. J Clin Exp Invest 2018;9:91-94. https://doi.org/10.5799/jcei.433817

10. Lee R, Vu K, Bell CM, Hicks LK. Screening for hepatitis B surface antigen before chemotherapy: Current practice and opportunities for improvement. Curr Oncol 2010;17:32-38.

11. Kose Ş, Olmezoğlu A, Gozaydın A, Ece G. Seroprevalance of hepatitis $B$ and $C$ among oncology patients in Turkey. J Health Popul Nutr 2011;29:652655.

12. Oguz A, Aykas F, Unal D, et al. Hepatitis B and $C$ seroprevalence in solid tumors - necessity for screening during chemotherapy. Asian Pac J Cancer Prev 2014;15:1411-1414. https://doi.org/10.1016/j. jfma.2012.10.007

13. Liu JY, Sheng YJ, Ding XC, et al. The efficacy of lamivudine prophylaxis against hepatitis $B$ reactivation in breast cancer patients undergoing chemotherapy: A meta-analysis. J Formos Med Assoc 2015;114:164173. https://doi.org/10.1016/j.jfma.2012.10.007

14. Yotsuyanagi H, Yasuda K, Moriya K, et al. Frequent presence of HBV in the sera of HBsAg-negative, antiHBc-positive blood donors. Transfusion 2001;41:10931099.

15. Hennig H, Puchta I, Luhm J, Schlenke P, Goerg S, Kirchner $\mathrm{H}$. Frequency and load of hepatitis $\mathrm{B}$ virus DNA in first-time blood donors with antibodies to hepatitis B core antigen. Blood 2002;100:2637-2641. doi.org/10.1182/blood-2002-03-0798

16. Dreier J, Kröger M, Diekmann J, Götting C, Kleesiek $\mathrm{K}$. Low-level viraemia of hepatitis B virus in an antiHBC- and anti-HBs-positive blood donor. Transfus Med 2004;14:97-103. https://doi.org/10.1111/j.09587578.2004.0486.x

17. Awerkiew $S$, Däumer $M$, Reiser $M$, et al. Reactivation of an occult hepatitis $B$ virus escape mutant in an antiHBs positive, anti-HBc negative lymphoma patient. J Clin Virol 2007;38:83-86. https://doi.org/10.1016/j. jcv.2006.10.006

18. Mikulska M, Nicolini L, Signori A, et al. Hepatitis $B$ reactivation in $\mathrm{HBsAg-negative/HBcAbpositive}$ allogeneic haematopoietic stem cell transplant recipients: risk factors and outcome. Clin Microbiol Infect 2014;20:O694-O701. https://doi.org/10.1111/14690691.12611 